\title{
The Impact of Leadership Styles on Employees Productivity in Organizations: A Comparative Study Among Leadership Styles
}

Roy Setiawan, Luigi Pio Leonardo Cavaliere, Enaidy Reynosa Navarro, Worakamol Wisetsri, Puttithorn Jirayus, Sapna Chauhan, Almighty C. Tabuena, and Regin Rajan,

\section{Authors}

Roy Setiawan, Universitas Kristen Petra, Universitas Airlangga, Indonesia. roy@petra.ac.id Luigi Pio Leonardo Cavaliere, Department of Economics, University of Foggia, Via Romolo Caggese, 1, 71121 Foggia FG, Italy. luigi.cavalie@gmail.com

Enaidy Reynosa Navarro, Vice-Rector for Research, Universidad César Vallejo, Perú. ereynosa@ucv.edu.pe

Worakamol Wisetsri, Department of Manufacturing and Service Industry Management, Faculty of Business and Industrial Management, King Mongkut's University of Technology North Bangkok, Bangkok Thailand. worakamol.w@arts.kmutnb.ac.th

Puttithorn Jirayus, Graduate school, Southeast Asia University, Bangkok, Thailand. puttithornj@sau.ac.th

Sapna Chauhan, Parul University, Gujarat, India. drsapnachauhan12@gmail.com

Almighty C. Tabuena, Senior High School Faculty Member, Department of High School Department, Espiritu Santo Parochial School of Manila, Inc. Philippines. almighty.tabuena@gmail.com

Regin Rajan, Department of Information Technology, Adhiyamaan College of Engineering, Tamil Nadu, India. regin12006@yahoo.co.in

\begin{abstract}
Successful leaders are facilitators who specifically target skilled and committed workers. Studies in organizational psychology and the research on an organization's actions suggest that management styles and staff motivation are key factors of business performance or failure. This study aimed to study the influence of leadership on the performance of employers in the education ministry and higher education of Somaliland and to define four types, namely, autocratic, transformational, democratic and transactional leadership. This study analyzed the effects of leadership styles on employee efficiency. The final findings have shown that the autocratic leadership model has a detrimental effect on the department's efficiency,
\end{abstract}


which is reflected in high absenteeism, poor morale, decline of job satisfaction, and rotation. The application of egalitarian, transformative and transactional leaders have a positive and important effect on the success of workers assessed by the high morale, efficiency, engagement, and dedication of the employees. The analysis aimed to explore the impact of leadership styles on employee achievement in the Somaliland Ministry of Education and Superior Studies and to define four major styles: autocratic, transformative, democratic and transactional management styles. Consequently, it is possible to assume that democratic, transactional and disruptive leadership has a positive connection to employee performance. In contrast, autocratic models often have a negative relation to employee results. It should also follow and further enhance its powerful aspects of practicing those features of democratic leadership that contribute positively to the company's success.

Keywords: Performance; Leadership; Autocratic; Democratic; Transformational; Transactional.

\section{Background of the study}

The success of organizations and the organization's development is always one of the main objectives of any association weather. Thus, staff effort combined with leadership styles affects the victory status of the organization [13]. The working environment changes dramatically, and the demand for product and service of the highest quality grows. Employee engagement is crucial to remain competitive in the face of these pressures. All organizations are aware of this reality [14]. Investigators acknowledge the key factors for organizational success and failure of employees' engagement and leadership styles [15].

Awais, M., et.al., [1] further indicate that continuous engagement is the product of the expectation that employee responsibilities are successfully handled and contribute to leadership performance benefits [16]. Management is one of the most pressing issues in the corporate world and is one of the least understood concepts. Leadership past contains many paradigm changes and comprehensive experience [17]. Leadership is essential for productive organization and social functioning as a universal practice. Its influence and results are the very nature of leadership [18]. The traits, structures, interpersonal perceptions, qualities and context in which the effect phase occurs are deciding this process. Leadership's spiritual aim is to build inspired followers who obtain moral results through religious means [19].

Many experiments on leadership types and attitudes were undertaken in the West. It is also long and away from knowing how politicians' function and conduct in other areas of the world, such as in less developed countries such as Africa and their connection to workers' success. This partly has given rise to our leaders' comprehension, since people's actions, ideas, and opinions are influenced by the cultural environments in which they exist, by analytical observations and discoveries of the West's academics [20]. 
Some scientists argue that there is no distinction between leadership styles and competencies seen by western and middle-eastern individuals [21]. At the same time, some cultural impact may help understand how leaders' function in other areas of the world. Leadership is a critical feature of an organization since leadership defines the bulk of an organization's performance and loss [22]. Leadership is a management activity that guides workers to meet job objectives in an immediate chain of command. It is now clear that staff engagement can be strongly affected by experiences with their immediate and senior supervisors and peers. The engagement is complicated and continuous and requires employers or managements to discover how their employees' working lives are improved [23].

Leadership plays a critical role in improving workforce retention, career motivation and efficiency [24]. To accept this point, big initiatives and resources, with differing degrees of effectiveness, have been extended to find and cultivate workers that can assume the leadership roles necessary to fulfil current and potential organizational requirements. Good leadership accelerates most organizations' development. It thus plays a vital role in organizational success [25]. In contrast, employee performance is an important cornerstone of an organization, and organizations must analyze the factors which provide the basis for high performance. Performance is a major multidimensional structure to achieve results, strongly linked to Barot, V., Kapadia, V., \& Pandya, S., [2] Leaders are not real leaders unless they have an emotional appeal, i.e., they must have followers and influence over a long period. Leadership builds on confidence, and confidence builds on the skill, honesty, integrity, openness, reaction, concern, and goodwill [26].

\section{Statement of the problem}

In 2002, the distinction between achievement and frailty had been related to leadership throughout the past, according to Fred Luthans, whether a battle, a business, a political movement or a basketball game [27]. In 2002 Gallup's survey shows that most employees believe that they are the boss, not the organization, which guides a culture and creates circumstances where employees can be glad and effective [28]. Leadership style is the form in which individuals are directed, applied and inspired. When workers see it, it requires the entire pattern of their leader's overt and implied behaviour [29]. There have been limited studies in Somaliland on ministry level employee efficiency, but some general studies shed light on the effect of leadership on employee performance [30]. This study has therefore attempted to fill this gap in the knowledge and research gap regarding leadership and employee performance in Somaliland in various ministries by examining the impacts of leadership styles on the ministry of education and leaders (e.g. autocratic, democratic, transformative and transactional leadership styles) [31]. 


\section{Importance of the trial}

It is expected that many stakeholders will benefit from this study [32]. First, it is useful for the ministry's managers and the ministry staff to better known themselves to establish a more harmonious and interdepartmental relationship. Also, it can assist teachers and students in using the institution's administration as a guide. Finally, other researchers use the vulnerabilities for further analysis and review [33].

\section{Leadership theories}

\section{The Trait Theory Paradigm}

Early studies in leadership are focused on the premise that leaders were not born. Researchers decided to define a variety of traits or characteristics that differentiate leaders from 10 or productive leaders [34]. Leadership hypotheses aim to clarify defining features that account for the success of leadership [35]. To define a sequence of attributes that all good leaders exhibited, the researchers analyzed physical and psychological characteristics or values such as high energy levels, appearance, hostility, self-confidence, persuasion and superiority [36]. The collection of features can be seen as a condition for supporting leadership candidates [37]. Leadership vacancies can only be granted to applicants who have the defined characteristics. Between the $1930 \mathrm{~s}$ and 1940s, a collection of qualities was identified among hundreds of characteristic reports. However, nobody has created a standardized list of characteristics that can ensure leadership success among all effective leaders. On the positives hand, while there is no set of features promising good leadership, features contributing to successful leadership have been established [38].

\section{Behavioural Theory}

In the late 1940s, scholars started to discuss the notion that the efficacy of leadership is decided by how an individual behaves [39]. The researchers analyzed habits and their effects on successful interventions such as the followers' development and happiness rather than looking for characteristics [40]. The superiority of philosophy and analysis in this direction relied on the belief that leaders must confront two differently. Still, interrelated facets of their situations: they must do the job and do it by others' efforts they command. They must do this. Therefore, all should be interpreted as referring to tasks and individuals even if many words have been used to describe such two-leadership reality [41]. Leaders' actions may be evaluated by evaluating what leaders do in the success of the mission and by retaining people's efforts [42]. Job-centered and staff-centred leadership Scholars have established two distinct management types, job-centred and employee-centred, by interviewing leading figures and followers [43]. The work chief: insists on finishing the mission and using tight tracking to execute subordinate activities utilizing such protocol [44]. 
Personal leaders concentrated on the personal success, development and accomplishment of their followers [45]. Such leaders stressed the growth of individuals and communities in the hope of successfully performing work [46]. Initiate Structure and Consideration Leadership One of the most important study programs in Ohio State University, established after World War II (OSU). This initiative contributed to creating a two-factor leadership philosophy that could concentrate both on jobs and workers [47]. A variety of experiments isolated two habits of leadership, defined as initiating and contemplating structure. The initiation of the structure (or function based on the words of Likert) includes conduct [48]. The leader organizes and establishes community ties and develops well-defined coordination patterns and networks, and describes how to get this job done [49]. The leader with a high systemic pattern reflects on targets and outcomes. Care (or employee-centred conduct in terms of Likert) includes pleasant, reciprocal confidence, respect, affection and partnership between the chief and the followers [50]. The widely esteemed chief advocates transparent collaboration and engagement [51].

\section{Contingency Approach}

Many leadership models clarify the interaction between leadership types and circumstances [52]. They are named contingency methods which comprise Hersey's and Blanchard's scenario theory, Fiedler's paradigm of leadership and his supporters, Evans and House's theory of the road and the idea of alternate leadership [53]. The situational theory of leadership is an interesting extension of conducting ideas summarized in the leadership grid [54]. In assessing acceptable management behaviour, the Hersey and Blanchard method relies a lot on followers' features. In Hersey and Blanchard's opinion, the degree of preparation of subordinates is distinct 55].

The situation theory notes that a leader should follow one of four leadership types, depending on a combination of relationships (personal concerns) and mission (production concerns) [56]. The style depends on how ready the followers are [57]. THE type of telling expresses a strong degree of commitment to duties and low regard for individuals and ties, and this extremely directive style gives clear guidance about how to execute the tasks [58]. Are both the individuals and the activities the selling type focused on a high degree of interest. In this method, the leader discusses choices and offers the subjects the ability to raise concerns, clarify and appreciate the activities [59].

There is a mixture of great care for individuals and partnerships, low concern for development tasks, and a participation design [60]. The leader discusses thoughts with colleagues, allows them the ability to contribute and makes decision-making simpler [61]. The form of delegation represents a low degree of consideration regarding partnerships and activities [62]. This type of leader gives no guidance and encouragement, for the leader delegates to subordinates' responsibilities for decisions and their execution [63]. It argues that good leadership is accomplished by choosing the best type of leadership, which relies on the followers' preparation. Accepting: the efficacy of leadership relies on whether adherents accept or refuse a chief. 
Preparedness: how well followers will and can execute a given role Produces four specific leadership types that combine the two dimensions of Fiedler's leadership [64]:

- Telling: strong task-low administration

- Sale: high task-high control of relationships

- Involvement: low task-high leadership

- Leadership: Medium task-low administration

- Four levels of preparation of the follower:

- R1: adherents cannot and do not want R1

- R2: follower cannot but be trained

- R3: supporters can't nor don't want

- R4: supporters are eager and ready

Fiedler's Contingency Theory

Although Hersey and Blanchard concentrated on followers' traits, Fiedler and his colleagues found several other factors in the corporate scenario to decide whether one leadership form is more successful than another [65]. Fiedler's philosophy starts with the degree to which the leader's style is mission or reference (peoples) [66]. Fiedler treated the leading style as somewhat set and impossible to alter, so the fundamental principle is to adopt the leader's style with the most appropriate scenario [68]. The right match may be organized by a diagnosis of leadership style and organizational standing [67].

\section{Path-Goal Theory}

Hersey and Blanchard concentrated on backers' traits, but Fiedler and his colleagues looked at several other aspects of the "path-goal theory", Another contingency approach to leadership. In compliance with the road-goal principle, the leader must improve his supporters' enthusiasm and demonstrate the direction to accomplish personal and organizational objectives [69]. This model comprises two sets of contingencies: leading actions and incentives to satisfy subordinates' desires. In Fiedler's philosophy, leaders should be modified as circumstances shift, but the pathgoal theory indicates that leaders will change their actions to accommodate the circumstance. These ranks are the leading actions that the leader should take, including encouraging, directing, success-oriented and participatory types. Constructive leadership means leadership behaviour, which indicates respect for the well-being and personal interests of subordinates [70].

Leader conduct is transparent, welcoming and responsive, and the leader promotes a team environment and respects others on an equal basis. Supportive leadership is identical to that mentioned above and is focused on individuals or partnerships. - The management takes place as the boss advises subordinates precisely what they can do. Leader conduct involves arranging and establishing success targets, complying with laws and laws, and aligning with behaviour norms. 
Directive leadership behaviour, as previously defined, is close to the initiation, work or taskbased leadership style. Participatory leadership means the chief informing his or her colleagues on decision making. Leading activity involves seeking opinions and recommendations, facilitating decision-making interaction and consulting colleagues at their workplaces. The leader promotes dialogue in groups and written feedback. A leadership geared towards success happens as the individual establishes simple and challenge targets for subordinates. Leader activity emphasizes high efficiency and improves current results. Leaders emphasizing accomplishment often express confidence in and support subordinates to learn how to meet high goals.

\section{Behavioural Leadership Styles}

The types of leadership are listed differently. Quoting Nwachukwu in 1988, Leland Bradford and Ronold Lippitt offered the autocratic, egalitarian and laissez-faire exemplified forms of leadership.

\section{Autocratic leadership style}

According to Bhopendra Singh, et al., [3] the so-called autocratic leadership approach contributes to nearly all officials depending on the chief. The leader enforces actions with incentives, and all who perform what they are ordered to do are fearful of rewards for retribution. Contact appears to go from the chief to the supporters in one way. Any circumstances may assist with the autocratic form of leadership. According to Terry, in an emergency and when the leader is smart, just and considerable, autocratic style leadership will work. The autocratic government may be in a low economic and social growth stage, where physiological and social fulfilment criteria stay lower. The autocratic form of leadership in Bhopendra Singh, et al., [3] can be extended where the followers have to be coerced, supervised and managed to carry out the function. Therefore, the autocratic model is one end of the leadership spectrum decision-making in this leadership style just inside the leader's province. Without informing the person doing the activities, the autocratic leader assigns, offers facilities and guidance. Such leadership may take positive or negative measures. If the strategy that stimulates and impacts people is mostly focused on terror and force, negative leadership is branded, and the tactics are known to be manipulative.

He who orders and experts obey the coercive king. The chief is dogmatic and responds to incentives and retribution by his willingness to offer or deny. Bhopendra Singh, et al., [3] says that if the leaders' strategies are focused on motivation and punishment, they would be defined as positive leaders who, by benevolence or coercion, are allowed to enforce their judgment. To get the desired outcome, the successful leader utilizes constructive strategies as praise, tact and diplomacy.

The manipulative chief tends to authorize the subordinates to engage in the mechanism of decision-making, but still, he retreats. He has a clever way to make his own choices while 
making sense of the subordinates' presence. The benefit of autocratic leadership is that decisions can be reached instantly, according to Bhopendra Singh, et al., [3]. Before settling, the chief shall not seek the permission of the community members. The impact of autocratic leadership on morality can be a possible downside. Members may contribute to actions being reached as few as practicable and therefore help them. Masters, too, who prefer to utilize leadership that essentially directs or commands workers that are less dedicated and deprived of autocratic leadership duty, are frequently short-lived.

\section{Democratic Leadership Style}

D.K. Sharma and D.S. Hooda [4] says that decision-making is exchanged by leaders and the party in a collaborative leadership model. Authority shall be autonomous, and the free flow of information facilitated. The party is clarified why the representative is obliged to take a vote of his own. The leader makes an overall monitoring and surveillance environment. In their opinion, the 2001 Okenwa and Ugbo model of democratic leadership is often regarded as a participatory or supportive leadership style. Essentially, the boss consults and allows subordinates to engage in planned acts and decisions. He also accepts the community he heads' ideas and critique. Ile 1999 claims that in democratic leadership, the representative proposes potential behaviour but expects the group's reactions before adopting them. Under certain cases, participatory leadership or encouragement is only a deceptive strategy when the manager pulls the levers behind the transparent conversation. Such a leader discussion with subordinates obtains his proposals and recommendations for difficult alternatives with any alternative advantages and drawbacks. Then he chooses, after a complete conversation, what to do. This is what is regarded as the collaborative advisory business.

However, where they are sincerely experienced, it is mainly a mental and emotional involvement of adherents to lead to the targets and to bear their share of the blame for achieving the objectives. It is founded on the premise that citizens want to engage, believe they are somebody or add to the final decision. The Superior encourages them to make contributions and utilize their teachers. He also allows you to complete your work. In cases where the leader and the subaltern community are information workers, this system is highly important.

D.S. Hooda and D.K. Sharma [5] the involvement of the management does not indicate that the subordinate determines what is achieved or not because the final judgment remains the duty of the chief. It is the mechanism of decision-making shared by representatives of the party. This is the style of leadership that contributes to what is referred to as objective management. The representative leadership style has multiple benefits, according to D.S. Hooda and D.K. Sharma [6] First, subordinates who engaged in establishing priorities and decision-making freely recognize. Any of the programs and their ability can even be utilized by subordinates. Better choices should be made in this situation. In reality, this leadership strategy is genuinely implemented and can assert management advantages through goals. 
According to citing D.S. Hooda and D.K. Sharma [7] identified some of the advantages of participatory leadership. The follower who took part in deciding what to do is likely to understand the decision and conclude that any course of action is appropriate and right. Thus, he has some courage and the chance to practice his talents and articulate himself. It motivates and inspires citizens to participate and take on obligations. On the other side, participatory leadership would allow him to consider his supporters' strength and experience that he can ask for and combine with him to create a collective and potentially better decision. Webber believes that administrators should train because they risk losing control and because it is challenging to submit. It takes time. It takes time. Slower decision-making, fewer transparency and potential concessions intended to appease all but not the right options are other drawbacks.

\section{Transformational Leadership}

Leadership in transition is a method to influence leaders to shift their partners' consciousness about what is essential and introduce them to a different outlook on themselves and their environment's possibilities and challenges. Transformation practitioners are constructive, striving to maximize the growth and creativity of people, communities and organizations, not merely achieving success "at expectations" They are persuading their workers to aim for better potential and stronger levels of morals and ethics. Transformation leadership does not substitute transactional management but raises it to meet the group's objectives. There is usually a sense of mission and a sense of family in a transformative way. Members and backers have similar values and a feeling of common destiny and interdependence. They go outside their desires or anticipated gains for the sake of the team and the organization. The introduction of transformative assumptions, expectations and ideals does not hinder the fulfilment of individual objectives and incentives. Superiors act as guides, trainers, role models and leaders and socialize individuals into the community, not only because they are supposed to do so but because they have a personal responsibility to enable potential participants to fit into the community.

D.S. Hooda and D.K. Sharma [8] say that Transition leaders can improve their followers by building on, empowering, partnering, encouraging, and developing their capacity. There is a rich collection of regulators, which provide a wide variety of behaviours, norms that can be tailored to and modified by external shifts in the corporate climate. Workers produce a strong degree of trust in such a chief. The workers are happy to recognize the chief and have a deep sense of allegiance to him. Similarly, D.S. Hooda and D.K. Sharma [9] argues that transformational leaders are important, especially as rapid shifts and globalization occur during tumultuous periods. Transformational leadership facilitates the growth of capability and brings a stronger personal dedication to corporate goals among the individuals who sustain them. D.S. Hooda and D.K. Sharma [10] argues that change leads arise as managers extend and enhance staff aspirations, boost knowledge and acceptance of the organization's priorities and missions, and inspire staff to look past the group's self-interest. Increased ability and dedication contribute to extra work and efficiency. 
D.S. Hooda and D.K. Sharma [11] transition leadership aims to alter the individuals' and organizations - to change them in mind, soul, and core. It's all about expanding the view, the perspective and the understanding, clarifying purposes, rendering actions compatible with ideals, concepts, or values. D.S. Hooda, Keerti Upadhyay and D.K. Sharma [12] favoured five considerations for transition leadership clarification. The five components proposed by the writers, as mentioned earlier, include human factors, intellectual stimulus, the incentive for creativity, idealization of power and idealized influence (behaviour).

\section{Transactional Leadership}

The staff works as independently of their peers as possible. Cooperation relies on the smooth settlement of negotiation and the shared task. The employees are little affiliated with the group, its purpose or its vision. Transactional leadership builds mostly on "exchanges" between the leader and the supporter who reward followers for achieving particular objectives or success requirements. The Supervisors are chiefly negotiators and resources allocators, The leader shall offer or mediate incentives and constructive strengthening. Transactional leadership is often more realistic, emphasizing achieving concrete goal. A successful transaction leader will consider and recompense the contributions of the followers on time. Subordinates to transactional representatives do not, therefore, inherently think innovatively and can be supervised by necessity.

Bad transactional leaders will not be more willing, though, to predict issues or interfere until problems come to light, whereas more productive transactional leaders take effective measures on time. The proactive method is referred to as contingent compensation, and management-byexception is the punitive style (active and passive). Transactional management identifies and encourages goals to reach these requirements. Contingent incentives are two central habits consistent with corporate 'management' tasks. Complete leaders are doing this and more. When contrasting transactional leadership styles, a transactional leadership style is ideal in certain contexts and may encourage conformity to procedure norms but not inherently accessible to creativity and risk. Transitional leadership provides a mission and encourages employees to aspire above goals, while transactional leadership concentrates more on external motivations for work.

Therefore, change leadership may affect perceptions through inspiring innovation acceptance by excitement, confidence, and transparency. In contrast, transactional leadership will contribute to innovation acceptability by enhancement and compensation. Bass explains the beginnings of his leadership philosophy that involves both transactional and transformational leadership to increase results. Bass has established a detailed management paradigm focused on his conviction that transition leadership and transactional leadership are not only a continuum. They are leadership patterns that all leaders have and use in different quantities. Transformational management habits should increase transactional management behaviours for exceptional results. 
Bass suggests, however, that transactional and transformational leadership activity toward subordinates is the highest accomplishment.

\section{Research Design}

The architecture for the thesis is essentially a research design. There are many types of study designs, but depending on the type of research and the issue's essence, the most suitable is selected. The study's analysis has been focused on hybrid techniques incorporating both quantitative and qualitative testing tools. To enhance the validity and reliability of the study outcome, the mixed method was proposed. The analysis framework was used in this research depending on the chosen research approaches. The relative study method is the best way to describe current problems related to the practice of management style and the impact on the workforce's work performance. This approach helps both qualitative and quantitative data to be represented. The study used a questionnaire and research interview survey to collect information from the Somaliland Ministry of Education and higher education.

\section{Sampling and Sample Techniques}

Sampling is the method or methodology for assessing the parameters or attributes of the entire population by choosing the required sample. The analysis used stratified sampling methods for the Department of Education and Higher Studies. The report's purpose was to involve staff from all agencies in the sample while providing the same opportunities to respondents to be chosen afterwards. The test was carried out in both likelihood samples and non-probability. Sampling techniques

\section{Data Gathering Tools}

Data collection methods are very critical to accomplish the expected goals. For the researcher to acquire the requisite data for this report, he will use the two common data collection instruments; the questionnaire and interview for the respondents and the semi-structured interview with the department's Director General.

\section{Questionnaire}

According to the company dictionary questionnaire, a collection of study or survey questions posed to respondents and structured to collect those details are given. It is structured for four essential purposes: to gather the necessary data, render data comparable and analysis-modifiable, eliminate prejudices in the formulation of questions, and make questions appealing and varied. The utility of this instrument requires gathering vast amounts of data from several individuals in the near term. Researchers or software bundles may rapidly and accurately measure the findings. The surveys were sent to the employee's respondents to gather the appropriate details. The survey was packed with 77 questionnaires and returned. Both self-prepared and modified questions were combined in the questionnaire, and the suitable questions were taken from 
Hussein 2014. The researcher has also prepared a questionnaire that is both accessible and closed to obtain input from workers.

\section{Methods of Data Analysis}

In the research review, data interpretation is important. Based on data processing and evaluation, the analyses and findings should arrive. The results were then analyzed according to the qualitative and quantitative quality of the data. The methodological packages for social science (SPSS) version 20 are the foundation for studying the data collected from respondents. The employee answers to the questionnaire would be evaluated using percentages, Chi-square and eventually regression analysis. Both main and secondary data are evaluated and quantitatively displayed by using methods such as percentiles, charts, diagrams, graphs and others to allow the analysis of data findings. Furthermore, the Ministerial Director's evidence during the interview will be evaluated and interpreted by discussions, which will help us clarify how various management models contribute to employee results. An autonomous management style will forecast employee output as a dependent variable.

\section{Validity and Reliability test}

The efficiency of the size of the random error-free data collection has been tested. The knowledge gathered is only useful if it is correctly registered. To be true in some calculation, reliability must be seen. The alpha of Cronbach's is a number. It is usually applied as an internal coherence or reliable indicator of a psychometric system. In other terms, it tests how effectively a series of variables or elements measure a particular latent one-dimensional feature of people. The Cronbach alpha should surpass the threshold to be sure, using the SPSS result. This demonstrates that the test objects display a strong degree of internal accuracy. From the above consequence, it can be inferred that the autonomous leadership style has some effect on the efficiency of the staff in the department but less and that this method of management has negatively impeded workers' performance because ALS produces aggressive behaviours, disputes, distortions and guard contact, high sales volumes, absenteeism, low pricing. The path is also producing yeasts who do not have imagination and ingenuity. They are mindful of all the obedience to laws, procedures, red tape and prestige, chasing icons, and always afraid of accountability.

In brief, many analyzes of regression have demonstrated that disruptive leadership positively forecasts employee efficiency. When managers have demonstrated more transformative management, workers work more successfully. The findings further show the optimistic and important effect on employers' efficiency of the practice of democratic leadership. This implies a high degree of staff efficiency, happiness, collaboration and dedication to democratic leadership. It eliminates the need for monitoring and official rules and procedures that contribute to workers' low absenteeism and attrition. Leadership produces professional and motivated workers prepared to do all they can to learn to interact freely and take accountability. The strong association 
between transactional leadership and employee success shows that management conduct includes incentives, emphasizes challenges, and strengthens the direction workers believe they can stick with the company. This relationship further reveals that the institutions with founders and supporters influence workers' spiritual affiliation and their sense of obligation. The t-values for the Autocratic and Transactional leadership coefficients are equal to two or above, as seen in the recession graph, where the coefficients of these two management models are statistically important and influence the output of the company's workforce. The coefficients are statistically appropriate. Except for the transformative and democratic leadership, this is not so.

\section{Regression Analysis}

Table 1. Model Summary

\begin{tabular}{|l|l|l|l|l|}
\hline Model & R & R Square & Adjusted R Square & Std. Error of the Estimate \\
\hline $\mathbf{1}$ & $\mathbf{0 . 5 2 8}^{\mathrm{a}}$ & $\mathbf{0 . 3 4 4}$ & $\mathbf{0 . 3 8 4}$ & $\mathbf{0 . 0 2 2 8 5}$ \\
\hline
\end{tabular}

a. Predictors: (Constant), Transactional, Autocratic, Transformational, Democratic

Table 2. Coefficients ${ }^{\mathrm{a}}$

\begin{tabular}{|c|c|c|c|c|c|}
\hline \multirow{2}{*}{\multicolumn{2}{|c|}{ Model }} & Unstandardized Coefficients & Standardized & $\mathbf{T}$ & Sig. \\
\hline & & B & Beta & & \\
\hline \multirow{3}{*}{1} & (Constant) & 0.017 & & 1.744 & 0.085 \\
\hline & Transactional & 0.427 & 0.354 & 3.656 & 0.031 \\
\hline & Transformational & 0.339 & 0.249 & 2.449 & 0.036 \\
\hline
\end{tabular}

Manuscript: Original published in: Productivity management, 26(1), GITO Verlag, P. 382-404, 


\begin{tabular}{|l|l|l||l|l|l|}
\hline Autocratic & 0.329 & 0.236 & 3.576 & 0.023 \\
\hline \multirow{2}{*}{ Democratic } & 0.429 & 0.258 & 5.23 & 0.036 \\
\hline
\end{tabular}

a. Dependent Variable: Performance

The model summary tables 1 and 2 explain the relationship among the dependent and independent variables using various indicators. The $\mathrm{R}$ constitutes $52.8 \%$, meaning that about $34.4 \%$ of the variables affect employee productivity. The R-Square tends to study the strength of the relationship among the variables indicating a $38.4 \%$, meaning that the transactional, transformational, autocratic and democratic. Lastly, the standard deviation is around 2\%, indicating a good normality distribution and that the data does not contain any bias.

Hence, upon referring to the above regression analysis, there is a direct relationship between the dependent and independent variables based on a significant error of $5 \%$. The results showed a significance level lower than $5 \%$, meaning that there is a correlation between the independent variables.

Employee Performance $=0.085+0.031$ transactional +0.036 transformational +0.023 Autocratic +0.036 Democratic

Hence, upon analyzing the outcome of the findings, the figures can be interpreted as follows:

- For every one-unit increase in "transactional leadership", the performance is positively affected by $1 \%$ since the regression analysis coefficient is positive, meaning that the relationship is a proportional relationship between transactional leadership and employees' performance.

- For every one-unit increase in "transformational", the performance is affected by $1.6 \%$.

As for the T-Test, it is another method used to validate the research hypothesis. This test should then specify a level above 2 to indicate a $95 \%$ significant level of validity.

Accordingly, the T-Test can be calculated by dividing Beta / Standard Error, which can be explained as follows:

- Transactional : $0.427 / 0.117=3.656$, meaning that transactional leadership tend to impact the performance by $3.65 \%$ 
- Transformational: $0.239 / 0.098=2.449$, meaning that transformational leadership tends to affect the employee's performance by $2.449 \%$

\section{Hypothesis Testing}

Hypothesis 1: Autocratic leadership models and job success have a substantial connection. As seen in the graph, the meaning value is 0.108 , which is higher than the meaning value at the 1 percent mark. Therefore, the coefficient value is higher, and the findings are significant, so the zero hypotheses should be dismissed. Then we may assume that the type of autocratic management influences the efficiency of workers.

Hypothesis 2: The transformational management style and employee success have a good connection. Therefore, the outcome is important and alternate theories are recognized, and the significance of this variable is greater than alpha $(0.178>.01)$. For that cause, it can be inferred from the regression findings that the transformational style has a significant and beneficial effect on the success of employees.

Hypothesis 3: The Democratic leadership style and employee success are both critical. Therefore, the conclusion is substantial, and an alternate explanation is acknowledged. The significance of such a variable is greater than alpha (0.452>.01). The regression findings also indicate that the implementation of the style of democracy has a constructive and important effect on employees' efficiency.

Hypothesis 4: Transactional management and employee success have a considerable partnership. The transactional leadership's importance may be deemed substantially impacting the company's employees' performances, as the value is greater than 0,017 . the null hypothesis can be dismissed

\section{Conclusions}

The analyst tried to uncover the most significant effects from the analysis. Without their managers, the workers of the organization cannot make their own choices individually. The boss neither allows them the incentive nor time for conversations for the vast majority of them' input and comments. And the great majority of them claim that their supervisors utilize incentives and penalties as their encouragement. Rather than autocratic types, though, autocratic leadership styles have a little or unfavourable effect on employee efficiency. The transformational approach is closely connected to indicators of employee success and a transformational leadership style. The study finds that the monitor encourages others to revisit the old issues and enables workers to obtain value through their jobs, thereby inspiring the workforce and showing successful results. Regarding the democratic leadership model, most of the respondents accepted that the style was more people-oriented, and there was greater contact within the community. The style allowed the workers to express their leadership position with their leader and the team's leader. 
In addition to providing a convenient atmosphere for delegating control and duties, the departmental managers were often able to interact regularly and efficiently with their staff. The staffs have also revealed that they are helped where they require it by their respective bosses and superiors. In brief, in the Ministry of Education and Higher Studies of Somaliland, the analysis found the essential values of democratic leadership. The type of transactional management is also tightly associated with the success and total performance of the employee. This style acknowledges and encourages workers to meet the goals they have to accomplish and advises them what to do when they wish to be recognized with their job. The most predominant types of leadership in Somaliland's Minister of Education and Higher Studies are transactional leadership.

\section{Limitation of the study}

During the analysis, the researcher dealt with several dropping. The first concern was a lack of time since the time allocated to carry out the analysis is six months. The researcher is also anticipated to gather the data outside Ethiopia, rendering the time too limited. The researcher's second challenge is the shortage of funds to administer questionnaires to the whole study group, which is why he drew a sample. The researcher also encountered budgetary problems to offset the costs incurring due to a shortage of sponsorship. Finally, the last challenge the researcher wished for was that respondents were not always able to complete the questionnaires; certain queries were left disappointed. Moreover, they will claim they are active and expected.

\section{Recommendations}

Depending on the outcome of the report, the management and leaders may be proposed as follows.

- Supervisors should explain goals and define priorities and criteria for followers to be reached. They do not delay before the issues get more serious and then take steps and track their success in good time. Supervisors can aim to respond to the concerns as quickly as possible if an issue occurs.

- Supervisors could not determine without inviting subordinates to make recommendations.

- Employees should be able to determine individually without their superiors' interference.

- Managers are greatly advised to spend time to share their input and feedback with their subordinates.

- Rewards and penalties should not be seen as motivational instrument.

It is also urged to further follow and improve its power in practising those characteristics related to its effectiveness in the democratic leadership form. Including:

- It must also build an atmosphere favourable to transfer power and obligation to workers.

- The organization must foster the production and practice of the culture of regular and successful contacts with its supervisors 
- To provide working workers with the fundamental values of democratic leadership such as friendliness, helpfulness and engagement motivation, the organization must arrange preparation to accomplish its organizational goals.

- Leaders or managers should be mindful of workers and organizations' value in general and inspire staff to take an innovative attitude to these openings and obstacles.

The Top Boss, as a Top Manager, suggests following the interview replies:

- Have administrators at all departmental levels of the decision-making phase.

- Each boss in the organization trains and equips each manager with the main leadership ingredients and empower him to communicate the production with his staff.

- A significant commitment in subordinate countries to resolve the detrimental impact of autocratic rule and turn this negative into constructive and revolutionary leadership forms.

- Supervisors can also have their vision and growth strategies, operate in communities and squad champions. In general, the investigator advises utilizing the department in a more transformative, democratic and transactional manner than autocratic leadership since it directly links to employee success and survival.

- This is also because the ministry's strategic preparation appears to be carried out with good staff participation, with priorities that, as these types are implemented, are specifically defined with their corresponding success targets.

\section{References}

[1]. Awais, M., Ghayvat, H., Krishnan Pandarathodiyil, A., Nabillah Ghani, W.M.; Ramanathan, A.; Pandya, S.; Walter, N.; Saad, M.N.; Zain, R.B.; Faye, I. Healthcare Professional in the Loop (HPIL): Classification of Standard and Oral Cancer-Causing Anomalous Regions of Oral Cavity Using Textural Analysis Technique in Autofluorescence Imaging. Sensors, 20, 5780, 2020.

[2]. Barot, V., Kapadia, V., \& Pandya, S., QoS Enabled IoT Based Low Cost Air Quality Monitoring System with Power Consumption Optimization, Cybernetics and Information Technologies, 20(2), 122-140, 2020.

[3]. Bhopendra Singh, S. Suman Rajest, K. Praghash, Uppalapati Srilakshmi and R. Regin. Nuclear structure of some even and odd nuclei using shell model calculations. Proceedings of the 2020 2nd International Conference on Sustainable Manufacturing, Materials and Technologies. AIP Conference Proceedings, 2020, https://aip.scitation.org/doi/abs/10.1063/5.0030932 
[4]. D.K. Sharma and D.S. Hooda. Generalized Measures of 'Useful' Relative Information and Inequalities. Journal of Engineering, Management \& Pharmaceutical Sciences, Vol.1(1), pp.15-21, 2010.

[5]. D.S. Hooda and D.K. Sharma. Lower and Upper Bounds Inequality of a Generalized 'Useful' Mean Code Length. GAMS Journal of Mathematics and Mathematical Biosciences, Vol. 4(1), pp.62-69, 2013.

[6]. D.S. Hooda and D.K. Sharma. Exponential Survival Entropies and Their Properties Advances in Mathematical Sciences and Applications, Vol. 20, pp. 265-279, 2010.

[7]. D.S. Hooda and D.K. Sharma. Bounds on Two Generalized Cost Measures. Journal of Combinatorics, Information \& System Sciences, Vol. 35(3-4), pp. 513-530, 2010.

[8]. D.S. Hooda and D.K. Sharma. Generalized 'Useful' Information Generating Functions. Journal of Appl. Math. and Informatics, Vol. 27 (3-4), pp. 591-601, 2009.

[9]. D.S. Hooda and D.K. Sharma. Non-additive Generalized Measures of 'Useful' Inaccuracy" Journal of Rajasthan Academy of Physical Sciences, Vol. 7(3), pp.359-368, 2008.

[10]. D.S. Hooda and D.K. Sharma, Generalized R-Norm information Measures-Journal of Appl. $\quad$ Math, Statistics \& informatics (JAMSI), Vol. 4 No.2, 153-168, 2008.

[11]. D.S. Hooda, Keerti Upadhyay and D.K. Sharma, 'Useful' R-Norm Information Measure and its Properties. IOSR Journal of Electronics and Communication Engineering, Vol. 8, pp. 52-57, 2013.

[12]. D.S. Hooda, Keerti Upadhyay and D.K. Sharma. Bounds on Cost Measures in terms of 'Useful' R-norm Information Measures. Direct Research Journal of Engineering and Information Technology, Vol.2 (2), pp.11-17, 2014.

[13].D.S. Hooda, Keerti Upadhyay and D.K. Sharma. A Generalized Measure of 'Useful Rnorm Information. International Journal of Engineering Mathematics and Computer Sciences, Vol 3(5), pp.1-11, 2014.

[14].D.S. Hooda, Keerti Upadhyay and D.K. Sharma. On Parametric Generalization of 'Useful' R- norm Information Measure. British Journal of Mathematics \& Computer Science, Vol. 8(1), pp. 1-15, 2015.

[15].D.S. Hooda, Sonali Saxena and D.K. Sharma. A Generalized R-Norm Entropy and Coding Theorem. International Journal of Mathematical Sciences and Engineering Applications, Vol.5(2), pp.385-393, 2011.

[16]. Dilip Kumar Sharma. Some Generalized Information Measures: Their characterization and Applications. Lambert Academic Publishing, Germany, 2010. ISBN: 9783838386041.

[17]. Ganguli S., Kaur G., Sarkar P., Rajest S.S. An Algorithmic Approach to System Identification in the Delta Domain Using FAdFPA Algorithm. In: Haldorai A., Ramu A., Khan S. (eds) Business Intelligence for Enterprise Internet of Things. EAI/Springer Innovations in Communication and Computing. Springer, Cham, 2020. 
[18]. Ghayvat, H., Pandya, S. Wellness Sensor Network for modeling Activity of Daily Living Proposal and Off-Line Preliminary Analysis. IEEE International Conference, Galgotias University, New Delhi, December 2018.

[19]. Ghayvat, H.; Awais, M.; Pandya, S.; Ren, H.; Akbarzadeh, S.; Chandra Mukhopadhyay, S.; Chen, C.; Gope, P.; Chouhan, A.; Chen, W. Smart Aging System: Uncovering the Hidden Wellness Parameter for Well-Being Monitoring and Anomaly Detection. Sensors, 19, 766, 2019.

[20]. Ghayvat, H.; Pandya, S.; Awais, M. ReCognizing SUspect and PredictiNg ThE SpRead of Contagion Based on Mobile Phone LoCation DaTa (COUNTERACT): A System of identifying COVID-19 infectious and hazardous sites, detecting disease outbreaks based on internet of things, edge computing and artificial intelligence, Sustainable Cities and Society, imf: 5.268, Elsevier.

[21]. Gupta J., Singla M.K., Nijhawan P., Ganguli S., Rajest S.S. An IoT-Based Controller Realization for PV System Monitoring and Control. In: Haldorai A., Ramu A., Khan S. (eds) Business Intelligence for Enterprise Internet of Things. EAI/Springer Innovations in Communication and Computing. Springer, Cham, 2020.

[22]. H. Ghayvat, Pandya, S., and A. Patel. Deep Learning Model for Acoustics Signal Based Preventive Healthcare Monitoring and Activity of Daily Living. 2nd International Conference on Data, Engineering and Applications (IDEA), Bhopal, India, pp. 1-7, 2020.

[23]. Jappreet Kaur, Tejpal Singh Kochhar, Souvik Ganguli and S. S Rajest. Evolution of Management System Certification: An overview. Innovations in Information and Communication Technology Series, pp. 082-092, 28 February, 2021.

[24].Kumar, S., Kumar, P., Wisetsri, W., Raza, M. \& Norabuena-Figueroa, R.P. Social entrepreneurship education: Insights from the indian higher educational courses. Academy of Strategic Management Journal, 20(S1),1-14, 2021.

[25]. Listiningrum, H. D., Wisetsri, W., \& Boussanlegue, T. Principal's Entrepreneurship Competence in Improving Teacher's Entrepreneurial Skill in High Schools. Journal of Social Work and Science Education, 1(1), 87-95, 2020.

[26]. Mehta, P., Pandya, S., A review on sentiment analysis methodologies, practices and applications, International Journal of Scientific and Technology Research, 9(2), pp. 601-609, 2020.

[27]. Pandya S, Wakchaure MA, Shankar R, Annam JR. Analysis of NOMA-OFDM 5G wireless system using deep neural network. The Journal of Defense Modeling and Simulation. 2021. doi:10.1177/1548512921999108

[28].Pandya, S., Ghayvat, H., Kotecha, K., Wandra, K., Advanced AODV Approach For Efficient Detection And Mitigation Of WORMHOLE Attack IN MANET, 10th IEEE International Conference on Sensing technology and Machine Intelligence (ICST-2016), Nanjing, China, November 2016. 
[29].Pandya, S., Ghayvat, H., Shah, J., Joshi, N., A Novel Hybrid based Recommendation System based on Clustering and Association Mining, 10th IEEE International Conference on Sensing technology and Machine Intelligence (ICST-2016), Nanjing, China, November 2016.

[30]. Pandya, S., H. Dandvate. New Approach for frequent item set generation based on Mirabit Hashing Algorithmll, IEEE International Conference on Inventive Computation technologies (ICICT), 26 August, India, 2016.

[31].Pandya, S., Patel, W., Mistry, V., i-MsRTRM: Developing an IoT based iNTELLIGENT Medicare System for Real-time Remote Health Monitoring, 8th IEEE International Conference on Computational Intelligence and Communications Networks (CICN-2016), Tehari, India, 23-25th December 2016.

[32]. Pandya, S., Shah, J., Joshi, N., Ghayvat, H., Mukhopadhyay, S.C. and Yap, M.H. November. A novel hybrid based recommendation system based on clustering and association mining. In Sensing Technology (ICST), 2016 10th International Conference on (pp. 1-6). IEEE, 2016.

[33].Pandya, S., Shah, J., Joshi, N., Ghayvat, H., Mukhopadhyay, S.C. and Yap, M.H. November. A novel hybrid based recommendation system based on clustering and association mining. In Sensing Technology (ICST), 2016 10th International Conference on (pp. 1-6). IEEE, 2016.

[34].Pandya, S., Sur, A. and Kotecha, K. Smart epidemic tunnel: IoT-based sensor-fusion assistive technology for COVID-19 disinfection. International Journal of Pervasive Computing and Communications, Emerald Publishing, 2020 Vol. ahead-of-print No. ahead-of-print, https://doi.org/10.1108/IJPCC-07-2020-0091.

[35].Pandya, S., Vyas, D. and Bhatt, D., A Survey on Various Machine Learning Techniquesll, International Conference on Emerging trends in Scientific Research (ICETSR-2015), ISBN no: 978-81-92346-0-5, 2015.

[36]. Pandya, S., W. Patel, An Adaptive Approach towards designing a Smart Health-care Real-Time Monitoring System based on IoT and Data Mining, 3rd IEEE International Conference on Sensing technology and Machine Intelligence (ICST- 2016), Dubai, November 2016.

[37]. Pandya, S., W. Patel, H. Ghayvat. NXTGeUH: Ubiquitous Healthcare System for Vital Signs Monitoring \&amp; Falls Detection. IEEE International Conference, Symbiosis International University, December 2018.

[38]. Pandya, S., Wandra, K., Shah, J., A Hybrid Based Recommendation System to overcome the problem of sparcity, International Conference on emerging trends in scientific research, December, 2015.

[39]. Pandya, S.; Ambient Acoustic Event Assistive Framework for Identification, Detection, and Recognition of Unknown Acoustic Events of a Residence, Advanced Engineering Informatics, Elsevier. http://www.sciencedirect.com/science/article/pii/S147403462030207X 
[40]. Pandya, S.; Ghayvat, H.; Kotecha, K.; Awais, M.; Akbarzadeh, S.; Gope, P.; Mukhopadhyay, S.C.; Chen, W. Smart Home Anti-Theft System: A Novel Approach for Near Real-Time Monitoring and Smart Home Security for Wellness Protocol. Appl. Syst. Innov. 2018, 1, 42, MDPI. https://doi.org/10.3390/asi1040042

[41]. Pandya, S.; Ghayvat, H.; Sur, A.; Awais, M.; Kotecha, K.; Saxena, S.; Jassal, N.; Pingale, G. Pollution Weather Prediction System: Smart Outdoor Pollution Monitoring and Prediction for Healthy Breathing and Living. Sensors, 2020, 20, 5448.

[42]. Patel, C.I.; Labana, D.; Pandya, S.; Modi, K.; Ghayvat, H.; Awais, M. Histogram of Oriented Gradient-Based Fusion of Features for Human Action Recognition in Action Video Sequences. Sensors, 20, 7299, 2020.

[43]. R. Regin, S. S Rajest and Bhopendra Singh. Spatial Data Mining Methods Databases and Statistics Point of Views. Innovations in Information and Communication Technology Series, pp. 103-109, 28 February, 2021.

[44]. Rajasekaran R., Rasool F., Srivastava S., Masih J., Rajest S.S. Heat Maps for Human Group Activity in Academic Blocks. In: Haldorai A., Ramu A., Khan S. (eds) Business Intelligence for Enterprise Internet of Things. EAI/Springer Innovations in Communication and Computing. Springer, Cham, 2020.

[45]. Rao, A. N., Vijayapriya, P., Kowsalya, M., \& Rajest, S. S. Computer Tools for Energy Systems. In International Conference on Communication, Computing and Electronics Systems pp. 475-484. Springer, Singapore, 2020.

[46]. Ravi Kumar Gupta. Employment Security and Occupational Satisfaction in India. Journal of Advanced Research in Dynamical \& Control System, Vol. 10, Issue 10, pp. 244-249, 2018.

[47]. Ravi Kumar Gupta. Minimum Wage and Minimum Work Hour in India. Journal of Advanced Research in Dynamical \& Control System, Vol. 11, 02-Special Issue, pp. 2402-2405, 2019.

[48]. Ravi Kumar Gupta, Dhirendra Bahadur Singh. Minimum Wage and Minimum Work Hour in India. The Journey of Single Taxation System: A Comprehensive study of GST in India, International Journal of Disaster Recovery and Business Continuity, Vol. 11, No. 03, p. 3022-3030, 2020

[49]. S. K. Khan et al. UAV-aided 5G Network in Suburban, Urban, Dense Urban, and Highrise Urban Environments. in 2020 IEEE 19th International Symposium on Network Computing and Applications (NCA), 2020, pp. 1-4: IEEE.

[50]. S. K. Khan, M. Farasat, U. Naseem, and F. Ali. Link-level Performance Modelling for Next-Generation UAV Relay with Millimetre-Wave Simultaneously in Access and Backhaul. Indian Journal of Science Technology, vol. 12, no. 39, pp. 1-9, 2019.

[51]. S. K. Khan, M. Farasat, U. Naseem, and F. Ali. Performance evaluation of nextgeneration wireless (5G) UAV relay. Wireless Personal Communications, vol. 113, no. 2, pp. 945-960, 2020. 
[52]. S. K. Khan, U. Naseem, H. Siraj, I. Razzak, and M. J. I. W. C. Imran. The role of unmanned aerial vehicles and mmWave in 5G: Recent advances and challenges. Transactions on Emerging Telecommunications Technologies, p. e4241.

[53]. S. S Rajest, D.K. Sharma, R. Regin and Bhopendra Singh. Extracting Related Images from E-commerce Utilizing Supervised Learning. Innovations in Information and Communication Technology Series, pp. 033-045, 28 February, 2021.

[54]. Shah, J., Pandya, S., N. Joshi, K. Kotecha, D. B. Choksi, Load Balancing in Cloud Computing: Methodological Survey on Different Types of Load Balancing Algorithmsll, IEEE International Conference on Trends in Electronics and Informatics, Tamil Nadu, India, May 2017.

[55]. Sharma M., Singla M.K., Nijhawan P., Ganguli S., Rajest S.S. An Application of IoT to Develop Concept of Smart Remote Monitoring System. In: Haldorai A., Ramu A., Khan S. (eds) Business Intelligence for Enterprise Internet of Things. EAI/Springer Innovations in Communication and Computing. Springer, Cham, 2020.

[56]. Singla M.K., Gupta J., Nijhawan P., Ganguli S., Rajest S.S. Development of an Efficient, Cheap, and Flexible IoT-Based Wind Turbine Emulator. In: Haldorai A., Ramu A., Khan S. (eds) Business Intelligence for Enterprise Internet of Things. EAI/Springer Innovations in Communication and Computing. Springer, Cham, 2020.

[57]. Souvik Ganguli, Abhimanyu Kumar, Gagandeep Kaur, Prasanta Sarkar and S. Suman Rajest. A global optimization technique for modeling and control of permanent magnet synchronous motor drive. Innovations in Information and Communication Technology Series, pp. 074-081, 28 February, 2021.

[58]. Srivastava A, Jain S, Miranda R, Patil S, Pandya S, Kotecha K. 2021. Deep learningbased respiratory sound analysis for detection of chronic obstructive pulmonary disease. PeerJ Computer Science 7:e369 https://doi.org/10.7717/peerj-cs.369, imf:3.09.

[59]. Sur S., Pandya, S., Ramesh P. Sah, Ketan Kotecha \& Swapnil Narkhede, Influence of bed temperature on performance of silica gel/methanol adsorption refrigeration system at adsorption equilibrium, Particulate Science and Technology, Taylor and Francis, impact factor: 1.7, 2020.

[60]. Sur, A., Sah, R., Pandya, S., Milk storage system for remote areas using solar thermal energy and adsorption cooling, Materials Today, Volume 28, Part 3, 2020, Elsevier, Pages 1764-1770, ISSN 2214-7853.

[61]. U. Naseem, I. Razzak, S. K. Khan, and M. Prasad. A Comprehensive Survey on Word Representation Models: From Classical to State-Of-The-Art Word Representation Language Models. arXiv preprint arXiv:.15036, 2020.

[62]. U. Naseem, M. Khushi, S. K. Khan, K. Shaukat, and M. A. Moni. A Comparative Analysis of Active Learning for Biomedical Text Mining. Applied System Innovation, vol. 4, no. 1, p. 23, 2021. 
[63]. U. Naseem, S. K. Khan, I. Razzak, and I. A. Hameed. Hybrid words representation for airlines sentiment analysis. in Australasian Joint Conference on Artificial Intelligence, pp. 381-392: Springer, 2019.

[64]. U. Naseem, S. K. Khan, M. Farasat, and F. Ali. Abusive Language Detection: A Comprehensive Review. Indian Journal of Science Technology, vol. 12, no. 45, pp. 1$13,2019$.

[65]. Vijai C.\& Wisetsri, W. Rise of Artificial Intelligence in Healthcare Startups in India. Advances In Management. 14 (1) March:48-52, 2021.

[66]. W. Wisetsri. The Perception of Brand Personality in the Context of Hotel of Undergraduate Students. vol. 3, no. 1, pp. 1-12, Jun. 2020.

[67]. Wisetsri, W. Man And Society (1st ed). Bangkok: King Mongkut's University of Technology North Bangkok, 2017.

[68]. Wisetsri, W. Spornosexual: Self-Esteem theory, present body characteristics by online media. Research and Development Journal Suan Sunandha Rajabhat University, 9(2): 24- 33, 2017.

[69]. Wisetsri, W.The Perception of Brand Personality in the Context of Hotel of Undergraduate Students. Journal of Multidisciplinary in Humanities and Social Sciences,3(1): 1-12, 2020.

[70]. Wisetsri,W. \& Maaz, U. D. The Influence of Leadership, Work Motivation and Organizational Culture on Job Performance. International Journal of Psychosocial Rehabilitation, 24(5):7336-7350, 2020. 